\title{
Information security in WSN applied to smart metering networks based on cryptographic techniques
}

\section{Autores}

Noel Varela, Omar Bonerge Pineda Lezama, Harold Neira

\begin{abstract}
The principle assaults on a Wireless Sensor Network (WSN) essentially influence the uprightness and accessibility of the data gathered, for example, Deni-al of Service, Blackhole, Wormhole, and assault on the data being transmitted. Privacy is not an important security objective because the data caught by the sensors are typically not delicate or mystery from individuals. A remote sensor organizes applied to shrewd metering frameworks might be adequately powerful as far as robotization and adjustment of the information that is gathered, however, if the system doesn't have satisfactory security, both the client and the organization offering the support might be influenced by assaults on the respectability and accessibility of the data transmitted. This research proposes the use of MESH encryption techniques and Star topology to find the best combination that meets the requirements of a Smart Metering System.
\end{abstract}

\section{Palabras clave}

Security, encryption, topology, WSN, smart metering networks, cryptographic techniques 